\title{
Development of Triglyceride Biosensor Based on the Polydopamine-Gold Nanocomposite
}

\author{
Min Zhu ${ }^{1}$, Zhang Yang ${ }^{2}$, Yongxia Cheng ${ }^{3}$, Yuanbo Sun ${ }^{4}$, Jian Xing $^{5}$, Jieru Wei $^{1}$, Jiping Sun ${ }^{1}$, \\ He Liu ${ }^{l}$ and Xiandong Song ${ }^{5, *}$ \\ ${ }^{1}$ Department of Radiology, HongQi Hospital Affiliated MuDanJiang Medical University, \\ MuDanJiang, HeiLongJiang Province, P.R. China \\ ${ }^{2}$ Department of Anatomy, MuDanJiang Medical University, MuDanJiang, HeiLongJiangProvince, \\ P.R. China \\ ${ }^{3}$ Department of Pathology, MuDanJiang Medical University, MuDanJiang, HeiLongJiangProvince, \\ P.R. China \\ ${ }^{4}$ Department of Nephrology, HongQi Hospital Affiliated MuDanJiang Medical University, \\ MuDanJiang,HeiLongJiang Province, P.R. China \\ ${ }^{5}$ Department of Radiology, HongQi Hospital Affiliated MuDanJiang Medical \\ University,MuDanJiang,HeiLongJiang Province, P.R. China \\ *E-mail: songxiandong@foxmail.com
}

doi: $10.20964 / 2017.07 .67$

Received: 26 March 2017 / Accepted: 5 May 2017 / Published: 12 June 2017

One significant factor in statin-induced type 2 diabetes (T2DM) predication is the concentration of triglyceride (TG). This study presents a polydopamine-gold nanocomposite (PDA/AuNPs)-based TG biosensor that features significant sensitivity. Au nanoparticles were found to exert remarkable enhancement of electrochemical responses. A double linear detection range with a low detection limit (DL) was exhibited by the prepared TG biosensor, which performed desirably in anti-interference. Hence, the designed PDA/AuNPs have potential as remarkable alternatives to TG detectors.

Keywords: Triglyceride; Type 2 diabetes; Gold; Polydopamin; Electrochemical sensor; Enzyme

\section{$\underline{\text { FULL TEXT }}$}

(C) 2017 The Authors. Published by ESG (www.electrochemsci.org). This article is an open access article distributed under the terms and conditions of the Creative Commons Attribution license (http://creativecommons.org/licenses/by/4.0/). 